\title{
High piezoelectric properties and good temperature stabilities of $\mathrm{CuO}$-modified $\mathrm{Ba}\left(\mathrm{Ti}_{0.96} \mathrm{Sn}_{x} \mathrm{Zr}_{0.04-x}\right) \mathrm{O}_{3}$ ceramics
}

\author{
Y. Q. Tan, J. L. Zhang* and C. L. Wang \\ School of Physics, State Key Laboratory of Crystal Materials, \\ Shandong University, Jinan 250100, P. R. China \\ *zhangjialiang@sdu.edu.cn
}

Received 26 May 2013; Revised 5 July 2013; Accepted 8 July 2013; Published 21 August 2013

\begin{abstract}
In order to obtain both high piezoelectric property and good temperature stability in $\mathrm{BaTiO}_{3}$-based ceramics in the common usage temperature range, $\mathrm{Sn}^{4+}$ and $\mathrm{Zr}^{4+}$ are co-doped into $\mathrm{BaTiO}_{3}$ ceramics according to the formula of $\mathrm{Ba}\left(\mathrm{Ti}_{0.96} \mathrm{Sn}_{x} \mathrm{Zr}_{0.04-x}\right) \mathrm{O}_{3}$ (BTSZ) $(x=0.01-0.4)$ with $1 \mathrm{~mol} \% \mathrm{CuO}$ being added as sintering-aid in this study. The CuO-modified BTSZ ceramics show both high piezoelectric properties and good temperature stability. Particularly, the CuO-modified $\mathrm{Ba}\left(\mathrm{Ti}_{0.96} \mathrm{Sn}_{0.01} \mathrm{Zr}_{0.03}\right) \mathrm{O}_{3}$ ceramic displays the high piezoelectric properties of $d_{33}=350 \mathrm{pC} / \mathrm{N}, k_{\mathrm{p}}=49.5 \%$ at room-temperature and a weak temperature dependence of $k_{p}$ in the temperature range of $-15^{\circ} \mathrm{C}$ and $60^{\circ} \mathrm{C}$. Moreover, the $\mathrm{CuO}$-modified $\mathrm{Ba}\left(\mathrm{Ti}_{0.96} \mathrm{Sn}_{0.01} \mathrm{Zr}_{0.03}\right) \mathrm{O}_{3}$ ceramic shows stable thermal aging behavior with the $d_{33}$ being almost unchanged until the aging temperature of $100^{\circ} \mathrm{C}$, which is even higher than its Curie temperature. The high piezoelectric properties of CuO-modified $\mathrm{Ba}\left(\mathrm{Ti}_{0.96} \mathrm{Sn}_{0.01} \mathrm{Zr}_{0.03}\right) \mathrm{O}_{3}$ ceramic were ascribed to the dense microstructure with small and uniform grain size distribution. The stable thermal aging behavior can be explained by the aging effect based on the defect dipolar model.
\end{abstract}

Keywords: Lead-free piezoelectric materials; $\mathrm{BaTiO}_{3}$-based ceramics; high piezoelectric activity; temperature stabilities; defect dipolar.

\section{Introduction}

Piezoelectric materials have been widely used in actuators, resonators, transducers, and other electronic devices. Among all those piezoelectric materials, $\mathrm{BaTiO}_{3}$ is the first material practically used to fabricate piezoelectric ceramics. However, for quite a long time, the $d_{33}$ of $\mathrm{BaTiO}_{3}$ ceramics had been reported to be only around $190 \mathrm{pC} / \mathrm{N},{ }^{1,2}$ which is much inferior to lead-based piezoelectric ceramics. Nevertheless, during recent years, a lot of progresses have been made on fabricating high-performance $\mathrm{BaTiO}_{3}$ piezoelectric ceramics with different sintering methods. ${ }^{3-6}$ Particularly, our research group has succeeded in fabricating high-performance $\mathrm{BaTiO}_{3}$ ceramics with $d_{33}$ as high as $419 \mathrm{pC} / \mathrm{N}$ through traditional solid-state reaction route with ordinary $\mathrm{BaCO}_{3}$ and $\mathrm{TiO}_{2}$ powders. ${ }^{7}$ This progress brings great hope that the $\mathrm{BaTiO}_{3}$ ceramics may become a popular type of lead-free piezoelectric materials.

However, due to the orthogonal-tetragonal phase transition around room-temperature, the piezoelectric properties of $\mathrm{BaTiO}_{3}$ ceramics show large temperature dependence. This may be a big obstacle in the practical application of $\mathrm{BaTiO}_{3}$ ceramics. In order to reduce the piezoelectric temperature dependence of $\mathrm{BaTiO}_{3}$ ceramics, $\mathrm{Ti}^{4+}$ was partially substituted with $\mathrm{Zr}^{4+}$ or $\mathrm{Sn}^{4+}$ in our previous studies so that the relatively temperature-stable orthogonal phase could be shifted to the common usage temperature range. ${ }^{8,9}$ Moreover, due to the high sintering temperature and relatively low piezoelectric properties of $\mathrm{Ba}(\mathrm{Ti}, \mathrm{Zr}) \mathrm{O}_{3}$ and $\mathrm{Ba}(\mathrm{Ti}, \mathrm{Sn}) \mathrm{O}_{3}$ ceramics, $\mathrm{CuO}$ was added as sintering-aid in the sintering process of the $\mathrm{Ba}(\mathrm{Ti}, \mathrm{Zr}) \mathrm{O}_{3}$ and $\mathrm{Ba}(\mathrm{Ti}, \mathrm{Sn}) \mathrm{O}_{3}$ ceramics. ${ }^{8-10}$ As a result, high $d_{33}$ values and good temperature stabilities were obtained simultaneously. However, when making a comparison between the $\mathrm{CuO}$-modified $\mathrm{Ba}(\mathrm{Ti}, \mathrm{Sn}) \mathrm{O}_{3}$ ceramics and the $\mathrm{CuO}$-modified $\mathrm{Ba}(\mathrm{Ti}, \mathrm{Zr}) \mathrm{O}_{3}$ ceramics, it was found that the former ones have higher $d_{33}$ values while lower Curie temperature, and the latter ones exhibit higher Curie temperature while lower $d_{33}$ value. So, in order to obtain higher $d_{33}$ values and better temperature stabilities simultaneously, $\mathrm{Sn}^{4+}$ and $\mathrm{Zr}^{4+}$ were co-doped with the formula $\mathrm{Ba}$ $\left(\mathrm{Ti}_{0.96} \mathrm{Sn}_{x} \mathrm{Zr}_{0.04-x}\right) \mathrm{O}_{3}$ (BTSZ) ceramics in this study. It was found that the $\mathrm{CuO}$-modified BTSZ ceramics all show high piezoelectric properties $\left(d_{33}\right.$ values greater than $\left.350 \mathrm{pC} / \mathrm{N}\right)$ and weak piezoelectric temperature dependence in the common usage temperature range. Moreover, all the $\mathrm{CuO}$-modified BTSZ ceramics exhibit good thermal aging stabilities.

\section{Experimental}

CuO-modified BTSZ $(x=0.01-0.04)$ ceramics were prepared using commercial powders of $\mathrm{BaCO}_{3}$ (purity $\geq 99.0 \%$, Sinopharm Chemical Reagent Co. Ltd.), $\mathrm{TiO}_{2}$ (purity $\geq 99.8 \%$, Xiantao Zhongxing Electronic Material Co. Ltd.), $\mathrm{SnO}_{2}$ (purity $\geq 99.8 \%$, Sinopharm Chemical Reagent Co. Ltd.) and $\mathrm{ZrO}_{2}$ (purity $\geq 99.8 \%$, Sinopharm Chemical Reagent Co. Ltd.) as starting materials. The raw materials were weighed according to the stoichiometric ratio, ball-mixed for $12 \mathrm{~h}$ in alcohol and calcined at $1050^{\circ} \mathrm{C}$ for $4 \mathrm{~h}$. Then, $1 \mathrm{~mol} \%$ $\mathrm{CuO}$ (purity $\geq 99.8 \%$, Sinopharm Chemical Reagent Co. Ltd.) 
powder was added into the synthesized BTSZ powder. The mixtures were ball-milled again for $12 \mathrm{~h}$. The powder was dried and further pressed into pellet discs of $15 \mathrm{~mm}$ diameter and $1.0 \mathrm{~mm}$ thickness. Sintering was performed in the air under the condition of $1190^{\circ} \mathrm{C}, 2 \mathrm{~h}$. For electrical evaluation, the sintered ceramics were coated with silver paint on the upper and bottom surfaces and fired at $575^{\circ} \mathrm{C}$ for 20 min. Poling was accomplished at $100^{\circ} \mathrm{C}$ in silicon oil under $3.0 \mathrm{kV} / \mathrm{mm}$ for $30 \mathrm{~min}$. The $d_{33}$ was measured with a Berlincourt-type $d_{33}$-meter (YE 2730, Wuxi). The $k_{\mathrm{p}}, k_{\mathrm{t}}, k_{33}$ and $Q_{\mathrm{m}}$ were obtained from resonance-antiresonance frequencies, which were measured using an Agilent 4294 A precision impedance analyzer. Thermal aging stability was assessed in such a way that the experimental specimen was first raised to the designed testing temperature and maintained for $1 \mathrm{~h}$. After being restored to room-temperature, the $d_{33}$ value was measured again. For characterizations of microstructure and domain configuration, the poled specimens were polished and chemically etched in a dilute $\mathrm{HCl}$ acid solution. Optical observation was performed under an Olympus BX51 polarizing microscope, and microscopic images were recorded by an Olympus DP70 digital camera. The polarization-electric field loops were measured using the Radiant Workstation (Germany).

\section{Results and Discussion}

Table 1 lists the mass density of various CuO-modified BTSZ ceramics as well as their dielectric and piezoelectric properties measured at room-temperature. It can be seen from Table 1 that all the CuO-modified BTSZ ceramics exhibit high density and good piezoelectric properties at room-temperature. With the decrease of $\mathrm{Sn}^{4+}$ concentration, the $d_{33}$ values decrease slightly from $400 \mathrm{pC} / \mathrm{N}$ to $350 \mathrm{pC} / \mathrm{N}$ while the $k_{\mathrm{p}}, k_{\mathrm{t}}$ and $k_{33}$ do not change much. In particular, the $\mathrm{CuO}-$ modified BTSZ ceramic with $x=0.01$ shows quite similar piezoelectric properties as $\mathrm{CuO}$-modified $\mathrm{Ba}\left(\mathrm{Ti}_{0.96} \mathrm{Sn}_{0.04}\right) \mathrm{O}_{3}$ ceramic, while the Curie temperature of $\mathrm{CuO}$-modified $\mathrm{Ba}$ $\left(\mathrm{Ti}_{0.96} \mathrm{Sn}_{0.01} \mathrm{Zr}_{0.03}\right) \mathrm{O}_{3}$ ceramic is much higher than that of $\mathrm{CuO}$-modified $\mathrm{Ba}\left(\mathrm{Ti}_{0.96} \mathrm{Sn}_{0.04}\right) \mathrm{O}_{3}$ ceramic. Figure 1 shows the temperature dependence of dielectric permittivity $\varepsilon^{\prime}$ for

Table 1. Room-temperature properties for various $\mathrm{CuO}$-modified BTSZ ceramics.

\begin{tabular}{lcccc}
\hline & $x=0.04$ & $x=0.03$ & $x=0.02$ & $x=0.01$ \\
\hline$\rho\left(\mathrm{g} / \mathrm{cm}^{3}\right)$ & 5.97 & 5.98 & 5.95 & 5.90 \\
$\varepsilon^{\prime}$ at $1 \mathrm{kHz}$ & 3450 & 3300 & 2900 & 3100 \\
$\tan \delta(\%)$ & 1.2 & 1.8 & 2 & 1.3 \\
$d_{33}$ & 400 & 380 & 360 & 350 \\
$k_{p}$ & 50.0 & 48.6 & 46.4 & 49.5 \\
$k_{t}$ & 47.0 & 45.8 & 44.4 & 45.7 \\
$k_{33}$ & 64.5 & 66.5 & 60.8 & 63.5 \\
$Q_{\mathrm{m}}$ & 391 & 221 & 248 & 310 \\
$T_{\mathrm{c}}\left({ }^{\circ} \mathrm{C}\right)$ & 82.1 & 87.6 & 91.5 & 97.9 \\
\hline
\end{tabular}

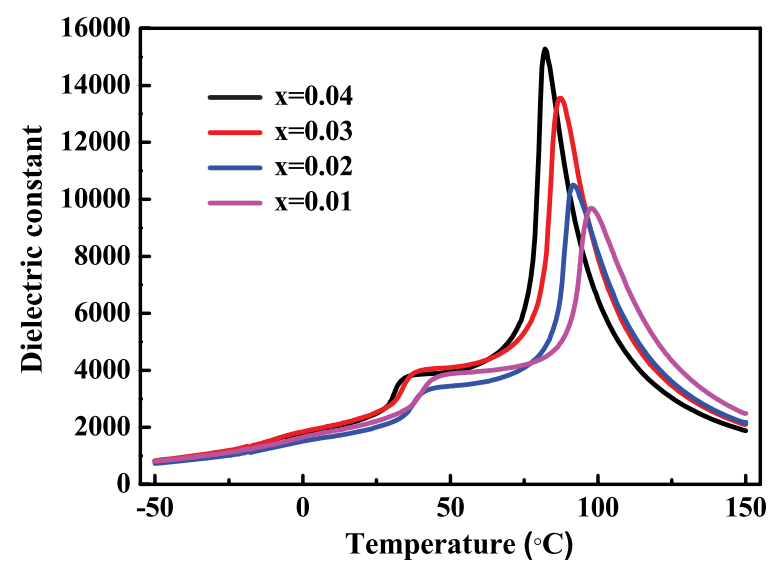

Fig. 1. Temperature dependence of dielectric permittivity $\varepsilon^{\prime}$ for various $\mathrm{CuO}$-modified BTSZ ceramics.

CuO-modified BTSZ ceramics. With the decrease of $x$, the Curie temperature $T_{\mathrm{C}}$ increases remarkably from $82.1^{\circ} \mathrm{C}$ to $97.9^{\circ} \mathrm{C}$. The orthorhombic-tetragonal phase transition temperature $\left(T_{\mathrm{O}-\mathrm{T}}\right)$ also shifts gradually from $35^{\circ} \mathrm{C}$ to about $45^{\circ} \mathrm{C}$ and the orthorhombic phase range is extended to high temperatures correspondingly.

The temperature dependences of $k_{\mathrm{p}}$ values for various CuO-modified BTSZ ceramics were presented in Fig. 2. It can be seen that in the commonly used temperature range, all the CuO-modified BTSZ ceramics show good temperature stabilities. Particularly, the CuO-modified $\mathrm{Ba}\left(\mathrm{Ti}_{0.96} \mathrm{Sn}_{0.01}\right.$ $\left.\mathrm{Zr}_{0.03}\right) \mathrm{O}_{3}$ ceramic show nearly temperature-independent high $k_{\mathrm{p}}$ values in the temperature range from $-1^{\circ} \mathrm{C}$ to $5^{\circ} \mathrm{C}$. Moreover, in the temperature range between $-50^{\circ} \mathrm{C}$ and $70^{\circ} \mathrm{C}$, the $k_{\mathrm{p}}$ values are all larger than $40 \%$. On the other hand, the $k_{\mathrm{p}}$ values are close to those of $\mathrm{CuO}$-modified $\mathrm{Ba}$ $\left(\mathrm{Ti}_{0.96} \mathrm{Sn}_{0.04}\right) \mathrm{O}_{3}$ ceramics in the commonly-used temperature range and higher than those of other CuO-modified BTSZ ceramics.

Figure 3 shows the thermal aging behavior of various $\mathrm{CuO}$-modified BTSZ ceramics in terms of $d_{33}$ values. It can

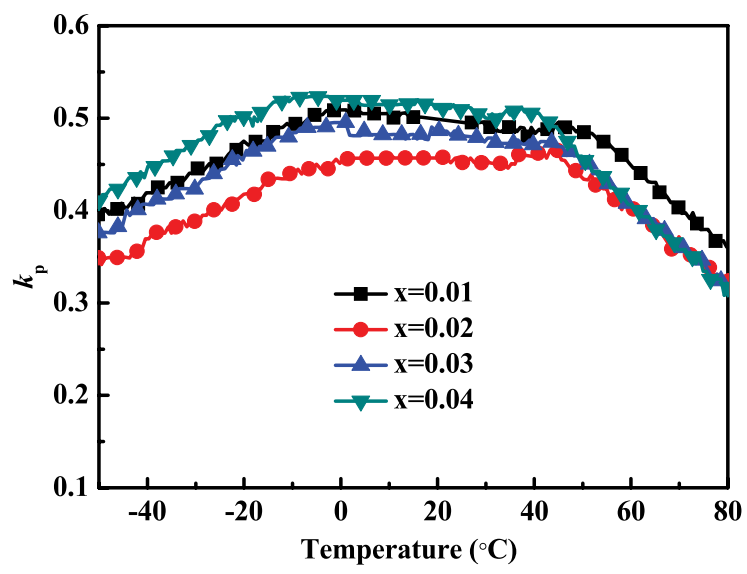

Fig. 2. Temperature dependence of $k_{\mathrm{p}}$ value for various $\mathrm{CuO}-$ modified BTSZ ceramics. 


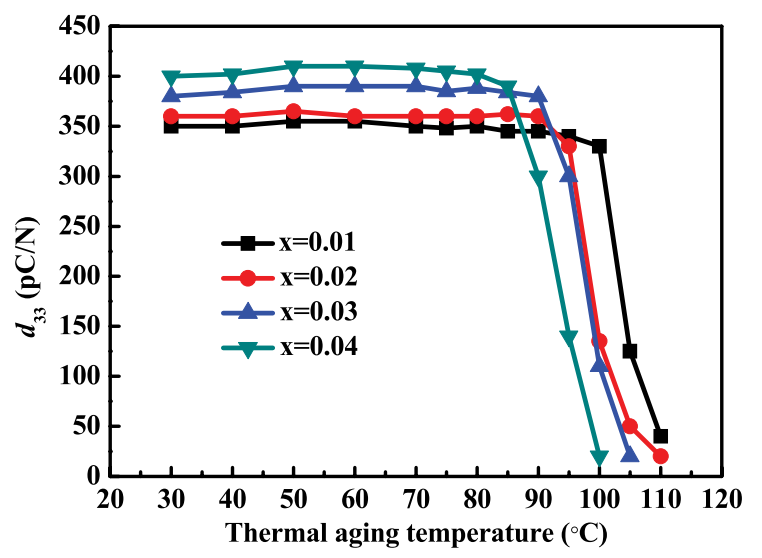

Fig. 3. Thermal aging behavior of various $\mathrm{CuO}$-modified BTSZ ceramics in terms of $d_{33}$ value.

be seen that all these ceramics show excellent thermal aging stabilities. The $d_{33}$ values of all these CuO-modified BTSZ ceramics kept almost unchanged until the thermal aging temperatures were nearly $5^{\circ} \mathrm{C}$ higher than their Curie temperatures. When the thermal aging temperatures were further raised, the $d_{33}$ values decreased drastically to about zero. The CuO-modified $\mathrm{Ba}\left(\mathrm{Ti}_{0.96} \mathrm{Sn}_{0.01} \mathrm{Zr}_{0.03}\right) \mathrm{O}_{3}$ ceramic shows the best thermal aging stability and the $d_{33}$ shows a temperature-independent value of $350 \mathrm{pC} / \mathrm{N}$ until the temperature of $100^{\circ} \mathrm{C}$.

The optical images of various CuO-modified BTSZ ceramics are shown in Fig. 4. It can be seen that all these
CuO-modified BTSZ ceramics show dense microstructures consisting of small and uniformly distributed grains. The CuO-modified $\mathrm{Ba}\left(\mathrm{Ti}_{0.96} \mathrm{Sn}_{0.01} \mathrm{Zr}_{0.03}\right) \mathrm{O}_{3}$ ceramic has the smallest average grain size of $3.5 \mu \mathrm{m}$ while the $\mathrm{CuO}$-modified $\mathrm{Ba}\left(\mathrm{Ti}_{0.96} \mathrm{Sn}_{0.02} \mathrm{Zr}_{0.02}\right) \mathrm{O}_{3}$ ceramic shows the largest average grain size of $12.5 \mu \mathrm{m}$. The average grain sizes for $\mathrm{CuO}$ modified $\mathrm{Ba}\left(\mathrm{Ti}_{0.96} \mathrm{Sn}_{0.03} \mathrm{Zr}_{0.01}\right) \mathrm{O}_{3}$ and $\mathrm{Ba}\left(\mathrm{Ti}_{0.96} \mathrm{Sn}_{0.04}\right) \mathrm{O}_{3}$ ceramics are $8.8 \mu \mathrm{m}$ and $9.5 \mu \mathrm{m}$, respectively. As to the domain structures, besides the $180^{\circ}$ - and $90^{\circ}$-domains, $60^{\circ}$ - and $120^{\circ}$ domains were also observed in these $\mathrm{CuO}$-modified BTSZ ceramics. The average domain widths for these $\mathrm{CuO}$-modified BTSZ ceramics do not vary much and are all around $380 \mathrm{~nm}$.

In the following part, we will discuss the possible mechanism for the high piezoelectric properties and good temperature stabilities of CuO-modified BTSZ ceramics. In our previous studies, we have demonstrated that the piezoelectric properties of $\mathrm{BaTiO}_{3}$ ceramics were much more stable in the orthorhombic phase than in the tetragonal phase. ${ }^{8}$ Partially substituting $\mathrm{Ti}^{4+}$ with $\mathrm{Sn}^{4+}$ or $\mathrm{Zr}^{4+}$ can shift the $T_{\mathrm{O}-\mathrm{T}}$ upward and extended the orthorhombic region. Compared with $\mathrm{Sn}^{4+}$ substitution, $\mathrm{Zr}^{4+}$ substitution is more effective in shifting the $T_{\mathrm{O}-\mathrm{T}}$ upward while keeping a higher Curie temperature. In Fig. 1, it can be seen that the $\mathrm{CuO}$ modified $\mathrm{Ba}\left(\mathrm{Ti}_{0.96} \mathrm{Sn}_{0.01} \mathrm{Zr}_{0.03}\right) \mathrm{O}_{3}$ ceramic shows the highest $T_{\mathrm{O}-\mathrm{T}}$ and $T_{C}$. On the other hand, the room-temperature piezoelectric properties of CuO-modified BTSZ ceramics usually decrease with the increase of $\mathrm{Zr}$ content. This could be interpreted in the following two aspects. First, the remnant polarization of $\mathrm{CuO}$-modified BTSZ ceramics will decrease

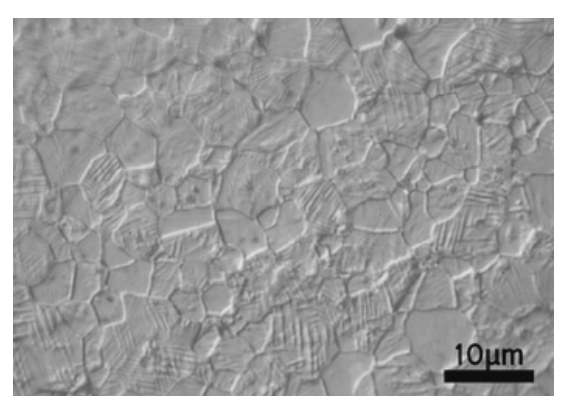

(a)

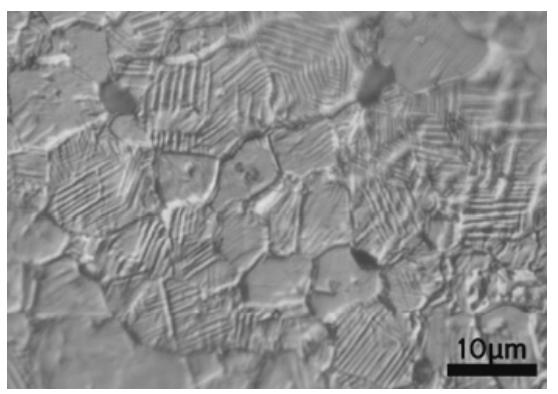

(c)

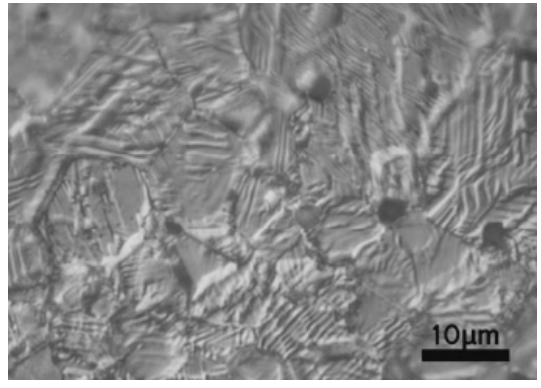

(b)

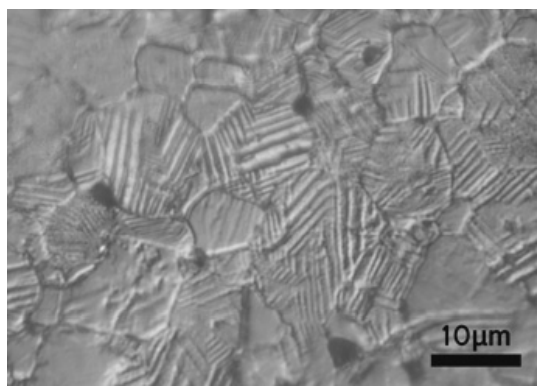

(d)

Fig. 4. The optical images of the domain structures for various CuO-modified BTSZ ceramics. (a) $x=0.01$; (b) $x=0.02$; (c) $x=0.03$; (d) $x=0.04$. 


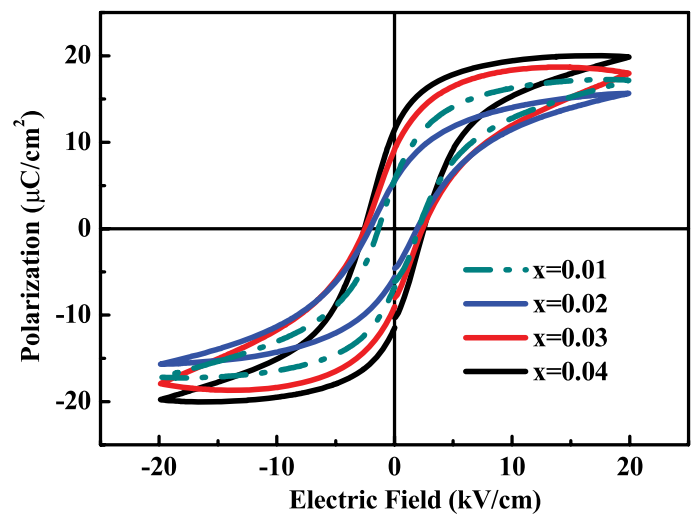

Fig. 5. Polarization versus electric field loop for various $\mathrm{CuO}-$ modified BTSZ ceramics.

with the increase of $\mathrm{Zr}$ content, as shown in Fig. 5. CuOmodified $\mathrm{Ba}\left(\mathrm{Ti}_{0.96} \mathrm{Sn}_{0.04}\right) \mathrm{O}_{3}$ ceramic shows the largest remnant polarization of $11.4 \mu \mathrm{C} / \mathrm{cm}^{2}$ and $\mathrm{CuO}$-modified $\mathrm{Ba}$ $\left(\mathrm{Ti}_{0.96} \mathrm{Sn}_{0.02} \mathrm{Zr}_{0.02}\right) \mathrm{O}_{3}$ and $\mathrm{Ba}\left(\mathrm{Ti}_{0.96} \mathrm{Sn}_{0.01} \mathrm{Zr}_{0.03}\right) \mathrm{O}_{3}$ ceramics show the similar remnant polarization of $5.6 \mu \mathrm{C} / \mathrm{cm}^{2}$. The second aspect is that with the increase of $\mathrm{Zr}$ content, the $T_{\mathrm{O}-\mathrm{T}}$ at which the $d_{33}$ of CuO-modified BTSZ ceramics reach the maximum values shifts upward. When measured at room-temperature, the $d_{33}$ of CuO-modified BTSZ ceramics become further away from the peak with the increase of $\mathrm{Zr}$ content. Nevertheless, in this study, the piezoelectric properties of CuO-modified $\mathrm{Ba}\left(\mathrm{Ti}_{0.96} \mathrm{Sn}_{0.01} \mathrm{Zr}_{0.03}\right) \mathrm{O}_{3}$ ceramic are quite close to the $\mathrm{CuO}$-modified $\mathrm{Ba}\left(\mathrm{Ti}_{0.96} \mathrm{Sn}_{0.04}\right) \mathrm{O}_{3}$ ceramic. This can be explained by the piezoelectric grain-size effect of $\mathrm{BaTiO}_{3}$ ceramics reported in our recent studies. ${ }^{11}$ It has been found that the piezoelectric constant $d_{33}$ of $\mathrm{BaTiO}_{3}$ ceramics increase significantly at room-temperature with the reduction of the average grain size $g$. The $\mathrm{CuO}$-modified $\mathrm{Ba}$ $\left(\mathrm{Ti}_{0.96} \mathrm{Sn}_{0.01} \mathrm{Zr}_{0.03}\right) \mathrm{O}_{3}$ ceramic shows the smallest average grain size. Therefore, the domain walls of $\mathrm{CuO}$-modified $\mathrm{Ba}$ $\left(\mathrm{Ti}_{0.96} \mathrm{Sn}_{0.01} \mathrm{Zr}_{0.03}\right) \mathrm{O}_{3}$ ceramic has smaller areas and lighter inertia masses, thus can respond more actively to an external electrical signal. ${ }^{12}$ The relatively low piezoelectric properties of CuO-modified $\mathrm{Ba}\left(\mathrm{Ti}_{0.96} \mathrm{Sn}_{0.02} \mathrm{Zr}_{0.02}\right) \mathrm{O}_{3}$ ceramic could be ascribed to the large average grain size.

The good thermal aging stabilities of CuO-modified BTSZ ceramics can be explained well by the aging effect based on the defect dipolar model. $\mathrm{Cu}^{2+}$ may partially replace $\mathrm{Ti}^{4+}$ in the sintering process and in order to maintain charge neutrality, an oxygen vacancy is formed around the $\mathrm{Cu}^{2+}$ in the oxygen octahedron. So in a unit lattice cell, there may be a defect dipole formed by $\mathrm{Cu}^{2+}$ and oxygen vacancy. The defect dipole can reorientate due to the mobility of the oxygen vacancy inside each oxygen octahedron. ${ }^{13,14}$ The reorientation of defect dipole is a hard diffusion process and may take several hours. Within a single domain, the defect dipoles tend to align parallel to the spontaneous polarization $P_{s}$ after aging because the energy is lowest in that case. ${ }^{15}$ Therefore, when the as-prepared CuO-modified BTSZ ceramics were poled, most of the spontaneous polarizations tend to align in the same direction. After aging for several hours, a large part of the defect dipoles will also align in the same direction and a large internal electric bias was formed. Therefore, the domain configurations of CuO-modified BTSZ ceramics are quite stable due to the aligned defect dipoles. ${ }^{16,17}$ Even when the aging temperatures were a little higher than their Curie temperatures, the CuO-modified BTSZ ceramics can still have high $d_{33}$ when cooled to room-temperature. When the aging temperatures were further raised, the oxygen vacancy has enough energy to diffuse randomly and the domain configurations become unstable at higher temperature, thus the $d_{33}$ decrease dramatically to zero.

\section{Conclusion}

In this study, $\mathrm{Sn}^{4+}$ and $\mathrm{Zr}^{4+}$ are co-doped in CuO-modified $\mathrm{BaTiO}_{3}$ ceramics. Compared with the single-doped CuOmodified $\mathrm{BaTiO}_{3}$ ceramics, the $\mathrm{CuO}$-modified $\mathrm{Ba}\left(\mathrm{Ti}_{0.96} \mathrm{Sn}_{0.01}\right.$ $\left.\mathrm{Zr}_{0.03}\right) \mathrm{O}_{3}$ ceramic exhibits both high piezoelectric properties and good temperature stabilities in the common usage temperature range. The high piezoelectric properties of $\mathrm{CuO}$ modified $\mathrm{Ba}\left(\mathrm{Ti}_{0.96} \mathrm{Sn}_{0.01} \mathrm{Zr}_{0.03}\right) \mathrm{O}_{3}$ ceramic are ascribed to the small average grain size. On the other hand, the $\mathrm{CuO}$ modified $\mathrm{Ba}\left(\mathrm{Ti}_{0.96} \mathrm{Sn}_{0.01} \mathrm{Zr}_{0.03}\right) \mathrm{O}_{3}$ ceramic shows a stable thermal aging behavior. This can be explained well with the defect dipolar model. Therefore, $\mathrm{CuO}$-modified $\mathrm{Ba}\left(\mathrm{Ti}_{0.96} \mathrm{Sn}_{0.01}\right.$ $\left.\mathrm{Zr}_{0.03}\right) \mathrm{O}_{3}$ ceramic could be considered as a promising low-cost lead-free piezoelectric material for practical applications.

\section{Acknowledgments}

This work was financially supported by the Natural Science Foundation of Shandong Province (Grant No. ZR2010EM005), the Specialized Research Fund for the Doctoral Program of Higher Education (Grant No. 20090131110015) and the National Natural Science Foundation of China (Grant No. 51172128).

\section{References}

${ }^{1}$ R. Bechmann, Elastic, piezoelectric, and dielectric constants of polarized barium titanate ceramics and some applications of the piezoelectric equations, J. Acoust. Soc. Am. 28, 347 (1956).

${ }^{2}$ B. Jaffe, W. R. Cook and H. Jaffe, Piezoelectric Ceramics (Academic, London, 1971).

${ }^{3}$ H. Takahashi, Y. Numamoto, J. Tani, K. Matsuta, J. Qiu and S. Tsurekawa, Lead-free Barium Titanate ceramics with large piezoelectric constant fabricated by microwave sintering, Jpn. J. Appl. Phys. 45, L30 (2006).

${ }^{4}$ T. Karaki, K. Yan, T. Miyamoto and M. Adachi, Lead-free piezoelectric ceramics with large diaelectric and piezoelectric constants manufactured from $\mathrm{BaTiO}_{3}$ nano-powder, Jpn. J. Appl. Phys. 46, L97 (2007).

${ }^{5}$ S. Wada, K. Takeda, T. Muraishi, H. Kakemoto, T. Tsurumi and T. Kimura, Preparation of [110] grain oriented Barium Titanate 
ceramics by templated grain growth method and their piezoelectric properties, Jpn. J. Appl. Phys. 46, 7039 (2007).

${ }^{6}$ H. Takahashi, Y. Numamoto, J. Tani and S. Tsurekawa, Considerations for $\mathrm{BaTiO}_{3}$ ceramics with high piezoelectric properties fabricated by microwave sintering method, Jpn. J. Appl. Phys. 47, 8468 (2008).

${ }^{7}$ S. F. Shao, J. L. Zhang, Z. Zhang, P. Zheng, M. L. Zhao, J. C. Li and C. L. Wang, High piezoelectric properties and domain configuration in $\mathrm{BaTiO}_{3}$ ceramics obtained through the solid-state reaction route, J. Phys. D: Appl. Phys. 41, 125408 (2008).

${ }^{8}$ P. Zheng, J. L. Zhang, S. F. Shao, Y. Q. Tan and C. L. Wang, Piezoelectric properties and stabilities of $\mathrm{CuO}$-modified $\mathrm{Ba}(\mathrm{Ti}, \mathrm{Zr})$ $\mathrm{O}_{3}$ ceramics, Appl. Phys. Lett. 94, 032902 (2009).

${ }^{9}$ J. L. Zhang, Z. Zhang, S. F. Shao, P. Zheng and C.L. Wang, High piezoelectric performance and relevant physical mechanism of CuO-modified $\mathrm{Ba}\left(\mathrm{Ti}_{0.96} \mathrm{Sn}_{0.04}\right) \mathrm{O}_{3}$ ceramics, J. Adv. Dielect. 1, 79 (2011).

${ }^{10}$ Z. Zhang, J. L. Zhang, S. F. Shao, P. Zheng and C. L. Wang, Influence of $\mathrm{CuO}$ additive on physical properties of $\mathrm{BaTiO}_{3}$ ceramics, Mater. Sci. Forum 687, 287 (2011).
${ }^{11}$ P. Zheng, J. L. Zhang, Y. Q. Tan and C. L. Wang, Grain-size effects on dielectric and piezoelectric properties of poled $\mathrm{BaTiO}_{3}$ ceramics, Acta. Mater. 60, 5022 (2012).

${ }^{12} \mathrm{G}$. Arlt and N. A. Pertsev, Force constant and effective mass of $90^{\circ}$ domain walls in ferroelectric ceramics, J. Appl. Phys. 70, 2283 (1991).

${ }^{13}$ W. L. Warren, K. Vanheusden, D. Dimos, G. E. Pike and B. A. Tuttle, Oxygen vacancy motion in perovskite oxides, J. Am. Ceram. Soc. 79, 536 (1996).

${ }^{14} \mathrm{C}$. Schaffrin, Oxygen diffusion in $\mathrm{BaTiO}_{3}$ ceramic, Phys. Stat. Sol. (a) 35, 79 (1976).

${ }^{15} \mathrm{G}$. H. Jonker, Nature of aging in ferroelectric ceramics, J. Am. Ceram. Soc. 55, 57 (1972).

${ }^{16} \mathrm{U}$. Robels and G. Arlt, Domain wall clamping in ferroelectrics by orientation of defects, J. Appl. Phys. 73, 3454 (1993).

${ }^{17}$ D. Z. Sun, X. B. Ren and K. Otsuka, Stabilization effect in ferroelectric materials during aging in ferroelectric state, Appl. Phys. Lett. 87, 142903 (2005). 